\title{
Familial Aggregation in Vitamin D Deficiency Disorder
}

Leila R. Farzin $^{1}$, Saeed Dastgiri ${ }^{2}$

1. Community and Family Medicine, Tabriz University of Medical Sciences, Tabriz, IRN 2. Tabriz Health Services Management Research Centre, Tabriz University of Medical Sciences, Tabriz, IRN

Corresponding author: Saeed Dastgiri, saeed.dastgiri@gmail.com

\section{Abstract \\ Introduction}

The relationship between vitamin D deficiency and some diseases (i.e., heart diseases, malignancies, and infectious diseases) has extensively been studied. There is, however, no epidemiological report on whether the familial predisposing factors have any role in the occurrence of vitamin D deficiency. The aim of this study was to investigate the familial aggregation of vitamin D deficiency disorder in the northwest region of Iran.

\section{Materials and Methods}

A total number of 930 individuals from the general population were invited/registered to the Family Medicine Clinic of Asadabadi Hospital, Tabriz University of Medical Sciences, Iran. A blood sample was obtained from subjects to measure the level of vitamin D. The blood tests were carried out by the enzymelinked immunosorbent assay method using Biorexfars diagnostics in the Asadabadi Hospital Laboratory. We calculated odds ratio (OR) with $95 \%$ confidence intervals ( $95 \% \mathrm{CI}$ ) to estimate the aggregation of vitamin D deficiency among relatives.

\section{Results}

We ascertained 580 cases with vitamin D deficiency disorder representing an overall prevalence rate of $62.4 \%$ (95\% CI: 59-65\%) in the northwest region. An aggregation of the vitamin D deficiency was found among brothers ( $\mathrm{OR}=1.55,95 \% \mathrm{CI}: 0.72-3.32)$, sisters $(\mathrm{OR}=1.24,95 \% \mathrm{CI}: 0.80-1.93)$, and spouses $(\mathrm{OR}=$ $1.18,95 \%$ CI: 0.76-1.82) of the cases. Other relatives (including parents, grandparents, grandchildren, aunts, nieces, and nephews) showed no aggregation of deficiency in the family in this study.

\section{Conclusion}

Our findings indicated that there might be an aggregational occurrence of vitamin D deficiency in some of the family members. Therefore, to be able to perform early preventive intervention, we would suggest testing the blood level of vitamin $\mathrm{D}$ for brothers, sisters, and spouse if one was diagnosed as having vitamin D deficiency.

Review began 10/07/2020 Review ended 04/18/2021 Published 04/25/2021

\section{() Copyright 2021}

Farzin et al. This is an open access article distributed under the terms of the Creative Commons Attribution License CC-BY 4.0., which permits unrestricted use, distribution, and reproduction in any medium, provided the original author and source are credited.
Categories: Endocrinology/Diabetes/Metabolism, Family/General Practice

Keywords: prevalence, vitamin d deficiency, familial aggregation, occurrence

\section{Introduction}

Vitamin D plays an important role in human health and meeting the biologic needs of human body. In the endocrine system, vitamin D controls the various parts of calcium hemostasis, especially in bone metabolism [1-3].

As a major public health problem, according to a systematic review and meta-analysis study, the overall prevalence of vitamin D deficiency was estimated to be $56 \%$ in the Iranian general population [4]. Another study found some degree of vitamin D deficiency in $84 \%$ of females and $68 \%$ of males among healthy children and adolescents living in the capital, Tehran [5]. A recent meta-analysis of 48 studies on 18,531 Iranian individuals estimated the prevalence of vitamin D deficiency for males (46\%), females (62\%), and pregnant women (60\%) in various geographical regions in Iran [6].

Genetic epidemiology examines the impact of genetic factors, environmental exposures, and the interaction between these two elements on the occurrence of a disease or a trait, and that how and why diseases, traits, and the related causes cluster in certain groups. Familial aggregation, as part of the genetic epidemiology, is the study of a group of individuals with a specific disease or trait to identify whether relatives have an excess occurrence of the same disease or trait. 
Little is known about the role of genetic and environmental factors, and the interaction in between, on the plasma level and deficiency of vitamin D. Wang and colleagues found a role for common genetic variants in regulation of circulating 25-hydroxy-vitamin D (25OHD) concentrations in a large group of 33,996 European descent individuals [7]. Another study on the 95 nuclear pedigrees in Russia showed that there was a very high pair-wise correlation between all members of families for $25 \mathrm{OHD}$, indicating that there might be a genetic factor transmitted within those families for 25OHD measures [8]. Similar evidence was found in school-aged children and their parents in nine Mesoamerican countries where the family aggregation of 25OHD concentrations was high among mothers and children [9].

The aim of this study was to investigate the familial aggregation of vitamin D deficiency disorder in the northwest region of Iran.

\section{Materials And Methods}

A total number of 930 individuals from the general population were invited/registered to the Family Medicine Clinic of Asadabadi Hospital, Tabriz University of Medical Sciences, Iran. We recruited 369 participants plus 561 of their family members, including brothers, sisters, spouses, mothers, fathers, grandmothers, grandfathers, grandchildren, aunts, and nephews for the assessment of vitamin D familial aggregation as hereditary, or as having a common lifestyle environment at home (i.e., husband and wife as spouses). As the inclusion and exclusion criteria for this study, none of the study subjects had a certain disease, did not use any particular medication, and gave informed consent for participating in this study. The blood samples were obtained from the study subjects in the morning following overnight fasting to measure the level of vitamin D. Blood tests were carried out by the enzyme-linked immunosorbent assay method (Awareness Technology Stat Fax 4200) using Biorexfars diagnostics (www.biorexfars.com) in the Asadabadi Hospital Laboratory. Based on the plasma level of the vitamin D in the study subjects, all amount less than 25 nanograms per milliliter $(\mathrm{ng} / \mathrm{ml})$ was considered as the deficiency of vitamin $\mathrm{D}$ in this study.

We calculated odds ratio (OR) with $95 \%$ confidence intervals (95\% CI) to measure the aggregation of vitamin D deficiency among relatives. The prevalence rate including $95 \% \mathrm{CI}$ was also estimated for the study population.

\section{Results}

The study participants $(\mathrm{n}=930)$ comprised $606(65.2 \%)$ female and $324(34.8 \%)$ male subjects recruited in Asadabadi Hospital. The mean \pm standard deviation age was $39.6 \pm 18.1$ with a median of 39 years.

We ascertained 580 cases with vitamin D deficiency disorder representing an overall prevalence of $62.4 \%$ (95\% CI: $59-65 \%$ ) in the northwest of the region. The prevalence rates were $60.9 \%$ (95\% CI: 57.0 $64.8 \%$ ) and $63.6 \%$ (95\% CI: 58.3-68.8\%) in females and males, respectively.

Figure 1 presents the familial aggregation of vitamin D deficiency in the family members and relatives of the study subjects. An aggregation of the vitamin D deficiency was found among brothers $(\mathrm{OR}=1.55,95 \% \mathrm{CI}$ : $0.72-3.32)$, sisters $(\mathrm{OR}=1.24,95 \% \mathrm{CI}: 0.80-1.93)$, and spouses $(\mathrm{OR}=1.18,95 \% \mathrm{CI}: 0.76-1.82)$ of the cases. Other relatives (including parents, grandparents, grandchildren, aunts, nieces, and nephews) showed no aggregation of deficiency of vitamin D in this study. 


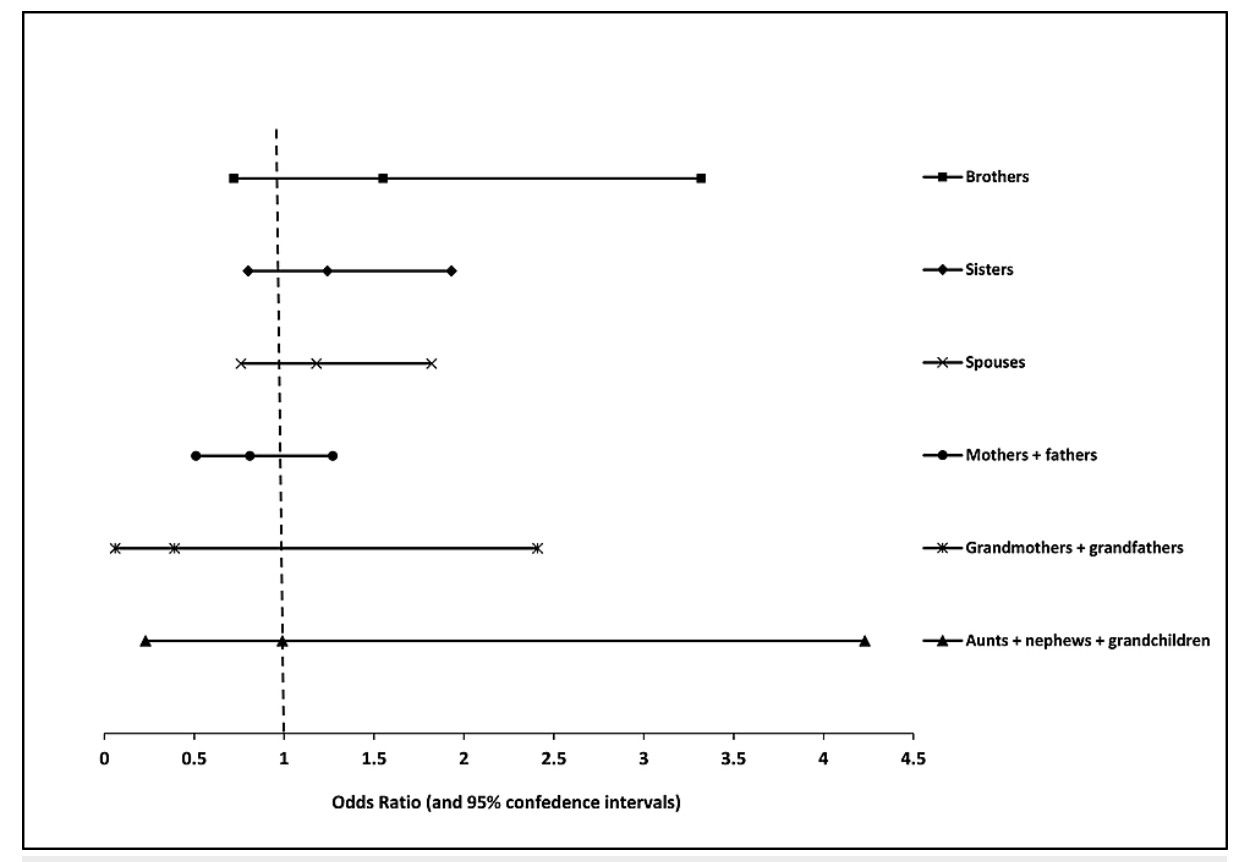

FIGURE 1: Familial aggregation of vitamin D deficiency in the family
members and relatives

\section{Discussion}

In this cross-sectional study, the prevalence and familial aggregation of vitamin D deficiency was investigated in a northwest region of Iran.

Very little is known about the occurrence of familial aggregation for chronic disorders in Iran. An aggregation of the risk factors of cardiovascular diseases has been reported from Kerman city in southern Iran [9]. We found that there is a familial aggregation of vitamin D deficiency among sisters, brothers, and spouses. Robinson et al. showed the familial aggregation for the same disorder among parents and children while we did not find the similar pattern in those family members [10].

This study showed that the occurrence of vitamin D deficiency is $61 \%$ and $64 \%$ in males and females, respectively. According to a systematic review in Iran, the prevalence of the deficiency of vitamin D was $62 \%$ in women and $46 \%$ in men [6]. The high occurrence of this disorder in various geographical areas in Iran indicates that this health problem needs to be considered as a priority of the healthcare system in the country, and a matter of large-scale etiological and preventive researches.

In a study conducted by Arora et al. in patients with prehypertension in the United States, $73 \%$ had vitamin $D$ deficiency where the serum level of vitamin $D$ in these patients was $15.7 \pm 6.3 \mathrm{ng} / \mathrm{ml}$ [11]. Almost consistent with the above study, $62 \%$ of our subjects had deficiency with $18.4 \pm 7.5 \mathrm{ng} / \mathrm{ml}$ of the serum level of vitamin D.

As for the limitations of this study, we did not have access to some socio-demographic and background data for statistical analysis of the occupation of participants, and the time duration of exposing to sunlight, as important factors in the occurrence of vitamin D deficiency. For the similar reason, we did not analyze the other potential factors related to the familial aggregation observed among the study participants to discuss whether they live together in one place under the same condition, or they have separate living with different lifestyle. Further investigations may then be required to clarify the independent role of genetics and environmental factors, and the interaction in between for the assessment of vitamin $\mathrm{D}$ deficiency disorder.

\section{Conclusions}

Although there is still no clear evidence about the role of genetic and environmental factors on the occurrence of vitamin D deficiency, our findings indicated that there might be an aggregational pattern of vitamin D deficiency in some of the family members. Therefore, to be able to perform early preventive intervention, we would suggest testing the blood level of vitamin $\mathrm{D}$ for brothers, sisters, and spouse if one was diagnosed as having vitamin D deficiency.

\section{Additional Information}




\section{Disclosures}

Human subjects: Consent was obtained or waived by all participants in this study. Ethics Committee of Tabriz University of Medical Sciences issued approval IR.TBZMED.REC.1397.122. Ethics approval was obtained from the Institutional Ethics Committee of Tabriz University of Medical Sciences. All test results and information from participants were treated strictly confidential assuring the research ethics are fulfilled. . Animal subjects: All authors have confirmed that this study did not involve animal subjects or tissue. Conflicts of interest: In compliance with the ICMJE uniform disclosure form, all authors declare the following: Payment/services info: All authors have declared that no financial support was received from any organization for the submitted work. Financial relationships: All authors have declared that they have no financial relationships at present or within the previous three years with any organizations that might have an interest in the submitted work. Other relationships: All authors have declared that there are no other relationships or activities that could appear to have influenced the submitted work.

\section{Acknowledgements}

The authors would like to acknowledge the assistance received from personnel at Asadabadi Hospital Laboratory. When we just started this project, we heard the sad news of the sudden and untimely death of our partner at this work, Dr Ali Akbar Alamolhoda. The authors were deeply touched by this immense and irreparable loss. May God give peace to his soul.

\section{References}

1. Holick MF: Sunlight and vitamin D for bone health and prevention of autoimmune diseases, cancers, and cardiovascular disease. Am J Clin Nutr. 2004, 80:1678S-88S. 10.1093/ajcn/80.6.1678S

2. Hagenau T, Vest R, Gissel TN, Poulsen CS, Erlandsen M, Mosekilde L, Vestergaard P: Global vitamin D levels in relation to age, gender, skin pigmentation and latitude: an ecologic meta-regression analysis. Osteoporos Int. 2009, 20:133-40. 10.1007/s00198-008-0626-y

3. Holick MF, Chen TC: Vitamin D deficiency: a worldwide problem with health consequences . Am J Clin Nutr. 2008, 87:1080S-86S. 10.1093/ajcn/87.4.1080S

4. Vatandost S, Jahani M, Afshari A, Amiri MR, Heidarimoghadam R, Mohammadi Y: Prevalence of vitamin D deficiency in Iran: a systematic review and meta-analysis. Nutr Health. 2018, 24:269-78. 10.1177/0260106018802968

5. Razzaghy-Azar M, Shakiba M: Assessment of vitamin D status in healthy children and adolescents living in Tehran and its relation to iPTH, gender, weight and height. Ann Hum Biol. 2010, 37:692-701. 10.3109/03014460903527348

6. Tabrizi R, Moosazadeh M, Akbari M, et al.: High prevalence of vitamin D deficiency among Iranian population: a systematic review and meta-analysis. Iran J Med Sci. 2018, 43:125-39.

7. Wang TJ, Zhang F, Richards JB, et al.: Common genetic determinants of vitamin D insufficiency: a genomewide association study. Lancet. 2010, 376:180-8. 10.1016/S0140-6736(10)60588-0

8. Livshits G, Karasik D, Seibel MJ: Statistical genetic analysis of plasma levels of vitamin D: familial study . Ann Hum Genet. 1999, 63:429-39. 10.1046/j.1469-1809.1999.6350429.x

9. Najafipour H, Mirzazadeh A, Haghdoost AA, et al.: Coronary artery disease risk factors in an urban and periurban setting, Kerman, southeastern Iran (KERCADR Study): methodology and preliminary report. Iran J Public Health. 2012, 41:86-92.

10. Robinson SL, Ramirez-Zea M, Roman AV, Villamor E: Correlates and family aggregation of vitamin D concentrations in school-aged children and their parents in nine Mesoamerican countries. Public Health Nutr. 2017, 20:2754-65. 10.1017/S1368980017001616

11. Arora P, Song Y, Dusek J, et al.: Vitamin D therapy in individuals with prehypertension or hypertension: the DAYLIGHT trial. Circulation. 2015, 131:254-62. 10.1161/CIRCULATIONAHA.114.011732 